\title{
Continuous Glucose Monitors are Cost Neutral Compared to SMBG
}

\author{
Tom Elliott ${ }^{1,2 *}$, and Arthur Weissinger ${ }^{1}$ \\ ${ }^{1}$ BC Diabetes, Canada \\ ${ }^{2}$ Division of Endocrinology, University of British Columbia, Canada
}

*Corresponding authors: Tom Elliott, BC Diabetes, Canada, Tel: 604-628-3734; E-mail: telliott@bcdiabetes.ca

Received: 03 Dec, 2020 | Accepted: 21 Dec, 2020 | Published: 28 Dec, 2020

Citation: Elliott T, Weissinger A (2020) Continuous Glucose Monitors are Cost Neutral Compared to SMBG. J Diab Res Ther 6(2): dx.doi. org/10.16966/2380-5544.155

Copyright: (C) 2020 Elliott T, et al. This is an open-access article distributed under the terms of the Creative Commons Attribution License, which permits unrestricted use, distribution, and reproduction in any medium, provided the original author and source are credited.

\begin{abstract}
Continuous Glucose Monitors (CGM) has revolutionized the management of diabetes and has become the standard of care for the management of Type 1 diabetes. The primary factor preventing widespread uptake of CGM is cost. Currently there is little provincial coverage for CGM, and many patients still must pay for the technology. The cost of CGM is here evaluated in comparison to standard care (self monitoring of blood glucose), including analysis of cost-savings and improvements in quality of life that could be achieved with the use of CGM. When costs of comorbidities and absenteeism that could be reduced by the use of CGM are included in the analysis, it is determined that CGM is cost-neutral relative to standard care.
\end{abstract}

Keywords: Continuous glucose monitor; Flash glucose monitor; Self monitoring of blood glucose; Hypoglycemia; Hyperglycemia; Diabetic ketoacidosis; Hypo; Type 1 diabetes; Economic benefit; Cost offsets; Quality of life

Abbreviations: CGM: Continuous Glucose Monitor; FGM: Flash Glucose Monitor; SMBG: Self Monitoring of Blood Glucose; DKA: Diabetic Ketoacidosis; Hypo: Hypoglycemia

Continuous glucose monitors (CGM) have revolutionized the management of diabetes and have become the standard of care for the management of Type 1 in most tertiary care diabetes centres.

The direct benefits of using CGM have been extensively documented [1-16]. CGM provides the ability to monitor and manage blood sugar levels in real time, resulting in improved glycemic control. This helps reduce the frequency and severity of hypoglycemic events and helps to prevent diabetic ketoacidosis, both of which can necessitate emergency care and hospitalization. Further, CGM is integral to closed-loop pump systems, which can provide an "artificial pancreas" function, further improving glycemic management. The use of CGM can lead to better overall control of diabetes, resulting in a marked improvement in quality of life.

The primary factor preventing widespread uptake of CGM is cost. While Wan W, et al. [17] found that CGM is cost effective from the perspective of the United States, Canadian provinces have been slow to reimburse for CGM even for those with type 1 diabetes. Of the Canadian provinces and territories, only the Yukon supports CGM. Quebec has full coverage, and Ontario restricted coverage for the Freestyle Libre ${ }^{\oplus}$, a Flash Glucose Monitor (FGM) that is less expensive than CGM. While most third-party insurers offer some coverage for CGM and FGM, more than 70\% of BC Diabetes clients are forced to pay for CGM and FGM out of pocket.

\section{Methods}

This paper establishes base costs of the various devices, and their comparator, Self Monitoring of Blood Glucose (SMBG), and factors in potential cost-offsets accruing from reductions in acute and chronic complications of diabetes resulting from the use of CGM to help maintain stable blood sugar levels. An estimate of the real cost of the technology must include these offsets, which in some cases affect the healthcare system directly. For example, the use of CGM is expected to result in a sharp reduction in the frequency and severity of hypoglycemic events, reducing or eliminating the need for emergency department visits and hospitalization required to treat them. Other offsets, such as that obtained from a reduction in absenteeism, while not affecting the healthcare system directly, still contribute to the real cost of CGM both to the individual and to the society.

The reader is referred to table 1 which addresses the incremental cost savings of CGM and FGM versus conventional SMBG using test strips, meter and lancets. For the purposes of this discussion the use of FGM (Freestyle Libre) is assumed to result in half the proportionate offset values calculated for the use of CGM for two reasons. 1) Unlike CGM devices which receive data pushed by a Bluetooth transmitter, FGM devices require data to be "pulled" from them, potentially causing rapid blood sugar excursions to be missed. 2) The FGM system lacks high and low blood sugar alarms, thus oncoming hypoglycemia and hyperglycemic events may not be recognized as quickly as with CGM. 
Table 1: CGM and FGM costs and cost offsets.

\begin{tabular}{|c|c|c|c|c|c|c|c|c|c|}
\hline A & B & C & D & $\mathbf{E}$ & $\mathbf{F}$ & $\mathbf{G}$ & $\mathbf{H}$ & I & J \\
\hline Brand Name & $\begin{array}{l}\text { Price/ } \\
\text { Day }\end{array}$ & $\begin{array}{l}\text { Price/Day } \\
\text { including } \\
\text { SMBG }\end{array}$ & $\begin{array}{c}\text { Savings } \\
\text { from fewer } \\
\text { hypos }\end{array}$ & $\begin{array}{c}\text { Savings } \\
\text { from fewer } \\
\text { DKAs }\end{array}$ & $\begin{array}{l}\text { Savings from } \\
\text { fewer late } \\
\text { complications }\end{array}$ & $\begin{array}{l}\text { Savings from } \\
\text { reduced } \\
\text { absenteeism }\end{array}$ & $\begin{array}{l}\text { Total Savings } \\
\text { with Device }\end{array}$ & $\begin{array}{l}\text { Net Device } \\
\text { Cost per day }\end{array}$ & $\begin{array}{c}\text { Savings vs } \\
\text { Standard } \\
\text { Care }\end{array}$ \\
\hline $\begin{array}{l}\text { Freestyle } \\
\text { Libre }^{\circ}+ \\
\text { Reader }\end{array}$ & $\$ 6.49$ & $\$ 7.30$ & $\$ 1.57$ & $\$ 0.58$ & $\$ 0.69$ & $\$ 1.07$ & $\$ 3.91$ & $\$ 3.39$ & $-\$ 0.15$ \\
\hline $\begin{array}{l}\text { Dexcom } \\
\text { G6 Annual } \\
\text { Subscription }\end{array}$ & $\$ 9.83$ & $\$ 10.64$ & $\$ 3.15$ & $\$ 1.16$ & $\$ 1.37$ & $\$ 2.14$ & $\$ 7.83$ & $\$ 2.81$ & $\$ 0.43$ \\
\hline $\begin{array}{l}\text { Medtronic } \\
\text { Guardian } \\
\text { Annual } \\
\text { Subscription }\end{array}$ & $\$ 9.83$ & $\$ 11.45$ & $\$ 3.15$ & $\$ 1.16$ & $\$ 1.37$ & $\$ 2.14$ & $\$ 7.83$ & $\$ 3.62$ & $-\$ 0.38$ \\
\hline $\begin{array}{l}\text { Standard } \\
\text { Care SMBG } \\
\text { Test Strips + } \\
\text { Lancets }\end{array}$ & $\$ 3.24$ & $\$ 3.24$ & N/A & N/A & N/A & N/A & N/A & $\$ 3.24$ & $\$ 0.00$ \\
\hline
\end{tabular}

\section{Results}

Table 1, columns B and C show the relative costs for SMBG, FGM and CGM systems. For the purpose of cost comparison with current standard of care (SMBG), it is assumed that each glucose test strip costs $\$ 0.75$ and each one-time use lancet costs $\$ 0.06$ (Freestyle Lite ${ }^{\circ}$ $\&$ Microlet $^{\circ}$ respectively, Costco pricing in BC on 2020-Aug-28). For the purposes of this report it is assumed that under standard care the average individual living with Type 1 diabetes performs SMBG 4 times per day (based on BC Pharmacare's estimate) for a cost of $\$ 3.24 /$ day (Table 1). Table 1 also lists the per-day cost of the CGM and FGM systems. The Freestyle Libre FGM system costs $\$ 6.49$ per day (sensor@ @89.00 lasting 14 days, and reader @ \$49.99 lasting one year; Costco pricing 2020-Aug-28). The two CGM systems currently available on the Canadian market, the Dexcom $\mathrm{G}^{\circ}$, and the Medtronic Guardian Connect are priced identically (manufacturers' pricing), with annual subscriptions resulting in a cost of $\$ 9.83$ per day for either system.

FGM and CGM systems do not eliminate the need for SMBG completely. All systems currently on the market require SMBG at least once daily for calibration. In table 1 , column $\mathrm{C}$ is shown the cost of the FGM or CGM systems with the additional cost of SMBG testing needed for calibration. Use of the Freestyle Libre and Dexcom G6 requires one SMBG per day, while the Medtronic Guardian system must be calibrated by SMBG twice each day.

\section{Fewer episodes of severe hypoglycaemia}

Table 1, columns D-H show the main cost offsets achieved with the use of CGM and FGM. Perhaps the most obvious source of savings is achieved by a reduction in hospitalization for severe hypoglycemia. Based on the work of Charleer S, et al. [3], a Belgian study which examined the economics of CGM, the proportion of patients admitted to hospital for hypoglycemia and/or ketoacidosis declined from $16 \%$ to $4 \%$ over the course of one year during which reimbursement for CGM was put in place for the test population. Diabetes-related hospital admissions per 100 patient years declined from 54 days at baseline to 18 days/100 patient years over this period, with the greatest benefit seen in hypoglycemia-related admissions.

Use of CGM is predicted to result in a reduction of hospitalization for severe hypoglycemia of 0.26 days per patient per year [3]. High acuity hospitalization required to treat severe hypoglycemia is estimated to cost approximately $\$ 4,425.00 /$ day in British Columbia. Reducing the frequency and severity of hypoglycemia through the use of CGM is expected to result in savings of approximately $\$ 3.15 /$ person/day (or \$1.57/day for FGM).

\section{Fewer episodes of diabetic ketoacidosis}

Charleer S, et al. [3] found that savings are also expected to be achieved by a reduction in the frequency of Diabetic Ketoacidosis (DKA). CGM is predicted to result in reduced hospitalization for DKA of 0.096 days per patient per year [3], at a hospitalization cost of $\$ 4,425.00 /$ day. Reduction of DKA through the use of CGM could result in a saving to the system of approximately $\$ 1.16 /$ patient/day, or $\$ 0.58 /$ day for FGM.

\section{Reduction in long-term hyperglycemic complications}

Further savings will be achieved by a reduction in long-term hyperglycemic complications. It has been estimated that with a reduction in Alc of $1.0 \%$, a reduction in microvascular events (nephropathy, retinopathy and neuropathic complications) and macrovascular events (e.g., heart disease, stroke and peripheral vascular complications), would be expected to result in average cost savings of approximately US $\$ 817$ per patient per year (average of US\$685 and US\$950; see P. 186 of Wagner EH, et al. $[18,19])$. In that study, significant cost savings were apparent within one year of achieving a lower A1c level.

Assuming $46 \%$ inflation since 2001and US exchange of 0.76 , US $\$ 817$ in 2001 translates into CAD $\$ 1566$ per patient per year or CAD $\$ 4.29$ per patient per day per $1 \%$ reduction in Alc on 2020 Aug-26 [20]. The Diamond study showed an average reduction in Alc at 24 weeks of $0.5 \%$ [7]. On this basis, predicted cost savings with $\mathrm{CGM}=\$ 4.29 / 2=\$ 2.14$ per patient per day. 


\section{Reduced work absenteeism}

Cost offset would also be achieved by a reduction in work absenteeism, although this would affect the individual and the society as a whole, rather than specifically contributing to the healthcare system. Based on Charleer S, et al. [3] CGM is predicted to result in a reduction of absenteeism from work of 2.607 days per patient per year. At an estimated cost of $\$ 192.00 /$ day, this reduction in work absenteeism is estimated to save the system $\$ 1.43$ per day [21].

\section{Costs not estimated}

Presenteeism, reduced work productivity while at work due to asymptomatic hypoglycemia, diabetic neuropathy and mood disorders is well recognized [22]. While we are unable to estimate the cost per person per day, presenteeism is known to contribute to lost productivity of approximately $\$ 26.9$ billion per year in the United States [23]. We have not attempted to put a dollar value (savings) on improved quality of life resulting from reduced anxiety and distress associated with hypoglycemia in general and overnight hypoglycemia in particular (broken nights' sleep for those living with diabetes and their caregivers). However, it is assumed that this could have a positive effect on the healthcare system by reducing the need for treatment of psychiatric illness associated with diabetes, a major and rapidly increasing cost to the Canadian healthcare system. We have also not addressed the value of the personal freedom experienced with the use of closed-loop pump systems made possible by CGM. Nor, conversely, have we addressed the potential economic cost of CGM-associated hypervigilance, an increasingly recognized phenomenon [24].

\section{Discussion}

The reader is directed to table 1 , column $\mathrm{H}$ which shows cost-savings predicted with the economic model discussed, which considered published, readily quantifiable economic benefits attributable to CGM. Column I shows net device cost after subtraction of estimated savings from base price plus SMBG. Column J shows the net savings of FGM and CGM compared to standard care. Compared to standard care (SMBG x 4 daily) savings range from $\$ 0.43$ (Dexcom G6) to -\$0.38 (Medtronic devices) per patient per day, not including potential economic benefits associated with improved quality of life.

The direct economic benefits of CGM are expected to accrue over the course of months to years. The quality of life benefits of CGM are expected to be experienced immediately. Wan W, et al. [17] found that CGM is cost effective for people with Type 1 diabetes at the willingnessto-pay threshold of $\$ 100,000$ per QALY, and made the statement that "with real-world use, CGM can be highly cost effective", in the United States. By "real-world" the authors imply that cost effectiveness can be achieved if CGM sensor wear, based on the Dexcom G5, can be extended from 7 to 10 days. Currently, the Dexcom G6 sensors allow for 10 days of wear, although the Medtronic Guardian is worn for a shorter period. Regardless of this difference, both systems, as well as the Freestyle Libre FGM are cost-effective in the Canadian context. We have found that the cost of CGM is fully offset by cost-savings associated with improved diabetes outcomes.

\section{Conclusions}

Our estimates, based on the published evidence and the cost of care in British Columbia, indicate that the use of either CGM or FGM is cost-neutral compared to standard care of SMBG. These estimates do not take into account, however, the potential benefits associated with improved quality of life, which could contribute positively to the healthcare system.
Because of the cost-neutrality of CGM and FGM, and because the use of these technologies is likely to have other positive effects, it is logical to include them among items for which the healthcare system should reimburse users. Indeed, as we have shown here, CGM actually has the potential to save money relative to the current standard of care.

\section{Supplemental Data}

The Minister of Health of British Columbia invited the author to outline the economic case for CGM. The result was a spreadsheet (http://bit.ly/2ZruLBL) that was shared with the Minister and has been kept up-do-date since. The spreadsheet serves as the basis for the estimates of costs and cost-offsets presented in this paper.

\section{References}

1. American Diabetes Association (2021) Diabetes Care: S111-S124.

2. Bailey T, Bode BW, Christiansen MP, Klaff LJ, Alva S (2015) The Performance and Usability of a Factory-Calibrated Flash Glucose Monitoring System. Diabetes Technol Ther 17: 787-794.

3. Charleer S, Mathieu C, Nobels F, De Block C, Radermecker RP, et al. (2018) Effect of Continuous Glucose Monitoring on Glycemic Control, Acute Admissions, and Quality of Life: A Real-World Study. J Clin Endocrinol Metab 103: 1224-1232.

4. Danne T, Nimiri R, Battelino T, Bergenstal R, Close KL, et al. (2017) International consensus on use of continuous glucose monitoring. Diabetes Care 40: 1631-1640.

5. Haak T, Hanaire H, Ajian R, Hermanns N, Riveline JP, et al. (2017) Flash Glucose-Sensing Technology as a Replacement for Blood Glucose Monitoring for the Management of Insulin-Treated Type 2 Diabetes: a Multicenter, Open-Label Randomized Controlled Trial. Diabetes Ther 8: 55-73.

6. Lind M, Polonsky W, Hirsch IB, Heise T, Bolinder J, et al. (2017) Continuous Glucose Monitoring vs Conventional Therapy for Glycemic Control in Adults with Type 1 Diabetes Treated with Multiple Daily Insulin Injections: The GOLD Randomized Clinical Trial. JAMA 317: 379-387.

7. Polonsky W, Hessler D, Ruedy K, Beck R, DIAMOND Study Group (2017) The Impact of Continuous Glucose Monitoring on Markers of Quality of Life in Adults with Type 1 Diabetes: Further Findings From the DIAMOND Randomized Clinical Trial. Diabetes Care 40: 736-741.

8. Reddy M, Jugnee N, Anantharaja S, Oliver N (2018) Switching from Flash Glucose Monitoring to Continuous Glucose Monitoring on Hypoglycemia in Adults with Type 1 Diabetes at High Hypoglycemia Risk: The Extension Phase of the I HART CGM Study. Diabetes Technol Ther 20: 751-757.

9. Reddy $M$, Jugnee $N$, Laboudi $A E$, Spanudakis $E$, Anantharaja $S$, et al. (2018) A randomized controlled pilot study of continuous glucose monitoring and flash glucose monitoring in people with Type 1 diabetes and impaired awareness of hypoglycaemia. Diabet Med 35: 483-490.

10. Shah VN, Laffel LM, Wadwa RP, Garg SK (2018) Performance of a factory-calibrated real-time continuous glucose monitoring system utilizing an automated sensor applicator. Diabetes Technol Ther 20: 428-433.

11. Wadwa RP, Laffel L, Shah VN, Garg SK (2018) Accuracy of a FactoryCalibrated, Real-Time Continuous Glucose Monitoring System During 10 Days of Use in Youth and Adults with Diabetes. Diabetes Technol Ther 20: 395-402. 
12. Welsh JB, Zhang X, Puhr SA, Johnson TK, Walker TC, et al. (2019) Performance of a Factory-Calibrated, Real-Time Continuous Glucose Monitoring System in Pediatric Participants with Type 1 Diabetes. J Diabetes Sci Technol 13: 254-258.

13. Diabetes Canada Clinical Practice Guidelines Expert Committee, Berard LD, Siemans R, Woo V (2018) Monitoring glycemic control. Can J Diabetes 42: S47-S53.

14. Edelman SV, Argento NB, Pettus J, Hirsch IB (2018) Clinical Implications of Real-time and Intermittently Scanned Continuous Glucose Monitoring. Diabetes Care 41: 2265-2274.

15. Ajjan R, Slattery D, Wright E (2019) Continuous Glucose Monitoring: A Brief Review for Primary Care Practitioners. Adv Ther 36: 579-596.

16. Brown SA, Kovatchev BP, Raghinaru D, Lum JW, Buckingham BA, et al. (2019) Six-Month Randomized, Multicenter Trial of Closed-Loop Control in Type 1 Diabetes. N Engl J Med 381: 1707-1717.

17. Wan W, Skandari MR, Minc A, Nathan AG, Winn A, et al. (2018) Costeffectiveness of Continuous Glucose Monitoring for Adults with Type 1 Diabetes Compared with Self-Monitoring of Blood Glucose: The DIAMOND Randomized Trial. Diabetes Care 41: 1227-1234.
18. Wagner EH, Sandh N, Newton KM, McCulloch DK, Ramsey SD, et al. (2001) Effect of improved glycemic control on health care costs and utilization. JAMA 285: 182-189.

19. Gilmer TP, O'Conner PJ, Manning WG, Rush WA (1997) The cost to health plans of poor glycemic control. Diabetes Care 20: 1847-1853.

\section{US INFLATION CALCULATOR}

21. Income of individuals by age group, sex, and income source, Canada provinces and selected metropolitan areas. Statistics Canada.

22. Mori K, Mori T, Nagata T, Nagata M, Iwasaki M, et al. (2019) Factors of occurrence and improvement methods of presenteeism attributed to diabetes: A systematic review. J Occup Health 61: 36-53.

23. American Diabetes Association (2017) Economic cost of diabetes in the U.S. in 2017. Diabetes Care 41: 917-928.

24. Messer LH, Johnson R, Driscoll KA, Jones J (2018) Best friend or spy: a qualitative meta-synthesis on the impact of continuous glucose monitoring on life with Type 1 diabetes. Diabet Med 35: 409-410. 